\title{
Maternal Food-Related Practices, Quality of Diet, and Well- Being: Profiles of Chilean Mother-Adolescent Dyads
}

\author{
Berta Schnettler, $\mathrm{PhD}^{1,2}$; Klaus G. Grunert, $\mathrm{PhD}^{3}$; Germán Lobos, $\mathrm{PhD}^{4}$; \\ Edgardo Miranda-Zapata, $\mathrm{PhD}^{5}$; Marianela Denegri, $\mathrm{PhD}^{2,6}$; Clementina Hueche, $\mathrm{MSc}^{2}$
}

\begin{abstract}
Objective: To identify mother-adolescent dyad profiles according to food-related parenting practices and to determine differences in diet quality, family meal frequency, life satisfaction, and sociodemographic characteristics.

Design: Cross-sectional study.

Setting: Mothers and children were surveyed in their homes or at schools in Temuco, Chile.

Participants: A total of 300 mothers (average age, 41.6 years) and their adolescent children (average age, 13.2 years; $48.7 \%$ female).

Main Outcome Measures: Maternal feeding practices using the abbreviated Family Food Behavior Survey (AFFBS), life satisfaction, food-related and family life satisfaction, diet quality, and eating habits.

Analysis: Principal component factor analysis and confirmatory factor analysis were used to verify Family Food Behavior Survey components in mother and adolescent subsamples. Hierarchical cluster analysis was used to identify profiles.

Results: Three AFFBS components were detected: maternal control of child snacking behavior, maternal presence during eating, and child involvement in food consumption. Cluster analysis identified 3 motheradolescent dyad profiles with different food-related parenting practices $(P \leq .001)$, mother $(P \leq .05)$ and child $(P \leq .001)$ diet quality, frequency of shared family meals $(P \leq .001)$, and mother $(P \leq .001)$ and child $(P \leq .05)$ life satisfaction levels.

Conclusions and Implications: Results indicated that maternal well-being increased with an increased frequency of shared mealtime. Significantly, in contrast to the findings of previous studies, greater control over child eating habits was shown to affect adolescent well-being positively. These findings, among others, may contribute to the development of strategies for improving diet quality, overall well-being, and wellbeing in the food and family domains for all family members.

Key Words: family meals, food-related parenting practices, profiles, subjective well-being (J Nutr Educ Behav. 2018;50:776-787.)
\end{abstract}

Accepted March 5, 2018. Published online April 3, 2018.

\footnotetext{
${ }^{1}$ Facultad de Ciencias Agropecuarias y Forestales, Universidad de La Frontera, Temuco, Chile ${ }^{2}$ Centro de Excelencia en Psicología Económica y del Consumo, Núcleo Científico y Tecnológico en Ciencias Sociales, Universidad de La Frontera, Temuco, Chile

${ }^{3}$ MAPP Centre, Aarhus University, Aarhus, Denmark

${ }^{4}$ Facultad de Economía y Negocios, Universidad de Talca, Talca, Chile

${ }^{5}$ LICSA, Núcleo Científico y Tecnológico en Ciencias Sociales, Universidad de La Frontera, Temuco, Chile

${ }^{6}$ Facultad de Educación, Ciencias Sociales y Humanidades, Universidad de La Frontera, Temuco, Chile

Conflict of Interest Disclosure: The authors have not stated any conflicts of interest.

Address for correspondence: Berta Schnettler, PhD, Facultad de Ciencias Agropecuarias y Forestales, Universidad de La Frontera, PO Box 54-D, Temuco, Chile; Phone: + (56-45 2325655; Fax: +(56-45) 2325634; E-mail: berta.schnettler@ufrontera.cl

(C) 2018 Society for Nutrition Education and Behavior. Published by Elsevier, Inc. All rights reserved.
}

https://doi.org/10.1016/j.jneb.2018.03.003

\section{INTRODUCTION}

There is increasing evidence that a high frequency of family meals is associated with positive outcomes for adolescents, such as a healthier diet. ${ }^{1-4}$ However, when healthful parenting practices such as providing healthful foods at home, modeling healthy food choices, and encouraging healthy eating ${ }^{4}$ are minimal, family meals do not seem to be positively associated with healthy food intake..$^{3,5}$ Obstacles in promoting healthy eating behaviors in adolescents include parents who are too busy and conflicting work and school schedules. ${ }^{6}$ This situation is relevant because the growing rate of 
maternal as well as paternal employment could result in fewer family meals and adolescents taking care of themselves to prepare and consume meals. ${ }^{3}$ When children eat alone, it has been found that their diet is unhealthy. ${ }^{4}$

The affective dimension of meals as a moment of family unity is an important component of the role of food within families, because family meals are an important ritual for socializing, preserving relationship closeness, resolving conflicts, expressing affection, and providing emotional support. ${ }^{7,8}$ The latter has been associated with healthier eating habits and a lower likelihood of obesity or being overweight among adolescents. ${ }^{9}$ In addition, family meals are important because they can increase the wellbeing of family members ${ }^{5,7,10}$ including adolescents. ${ }^{11-13}$ Subjective well-being is a multidimensional category of phenomena involving emotional responses, positive and negative affect, and global judgments of life satisfaction in different domains. ${ }^{14}$ Life satisfaction is the assessment one makes regarding one's overall life or specific life domains. ${ }^{15}$ Regarding the food domain, food-related life satisfaction is a person's overall assessment of his or her food and eating habits. ${ }^{16}$ Some studies suggest that food-related life satisfaction is positively correlated with overall life satisfaction. ${ }^{10,17,18}$ Higher levels of life and food-related life satisfaction have been positively associated with better eating habits, greater frequency and increased importance assigned to family meals, and greater family support. ${ }^{5,10,18,19}$ In fact, it was reported that adults and emerging adults who share meals with their family more often are more satisfied with their life, their food-related life, ${ }^{5,10,18,19}$ and their family life. ${ }^{5}$ However, the relationship between the frequency of family meals and adolescent well-being in the food and family domains is unclear. ${ }^{5}$ In parallel, relationships among well-being, eating habits, and family relationships are not homogeneous and different subject profiles have been distinguished based on these variables. $5,10,18,19$

Parents use different food-related parenting practices to influence child food intake, although research on the combined effect of several parental feeding practices is scarce. ${ }^{20}$ At the same time, previous studies found conflicting results regarding the effect of food-related parenting practices on adolescent eating habits. ${ }^{3,12,21-23}$ For instance, some studies associated a lower intake of fruits and vegetables with less parental control over meals, ${ }^{3,23}$ whereas others reported that higher levels of parental control were related to the increased consumption of unhealthy foods, overeating, ${ }^{21,24}$ and being overweight. ${ }^{25}$ Likewise, it was reported that adolescent involvement in food preparation is a positive factor affecting diet quality in this age group. ${ }^{3,21}$ However, others showed that increased child influence on food planning and preparation results in less healthy food choices. ${ }^{23}$ However, parental influence via food-related parenting practices depends on the parent's presence and involvement in family meals. ${ }^{3}$ Some authors suggested that a low frequency of family meals 3,26 may be related to less parental monitoring and control over meals ${ }^{3}$ as well as less food-related family interaction, including adolescent involvement in food preparation. ${ }^{13}$ In addition, it was suggested that maternal presence when a child eats produces a protective effect on that child's weight status. ${ }^{25}$ Therefore, it is possible that the outcomes of food-related parenting practices may be related to the frequency of meals in which at least 1 parent is present and shares the meal with children at home. It may also be related to the food-related parenting practices used (or the lack of them) when parents share meals with their children.

Regardless of these possibilities, little is known about the outcomes of different food-related parenting practices on adolescent well-being. ${ }^{11,12}$ Nevertheless, these practices may also have both positive and negative outcomes on adolescent well-being. A recent study reported that controlling foodrelated parenting practices may have a protective effect against adolescent risk for becoming overweight or obese, ${ }^{27}$ thus positively affecting adolescent well-being. ${ }^{28}$ However, others reported that this kind of practice may be associated with a greater risk for adolescent obesity and overweight ${ }^{29}$ as well as with eating disorders and higher levels of anxiety and depression. ${ }^{30}$ All of these factors are related to lower adolescent well-being. ${ }^{28}$ Utter and colleagues $^{13}$ found that adolescent cooking ability was associated with better family relationships and wellbeing and lower levels of depression, whereas adolescents who cooked most days or never cooked were more likely to report poorer family relationships, lower well-being, and greater levels of depression..$^{13}$ Although family meals were associated with increased family member well-being, ${ }^{5,7,10-13}$ family meals might also be a source of tension, resulting in their being avoided or shortened. ${ }^{26}$ In addition, it has been reported that a low frequency of family meals as well as a negative atmosphere during the time they are shared may negatively affect adolescent well-being. ${ }^{31}$ Therefore, considering that adolescents' family relationships, which are affected by food-related parenting practices, are closely related to adolescents' well-being, ${ }^{5,32}$ this research expects to uncover relationships between different food-related parenting practices and adolescent wellbeing, both in general and in the food and family domains.

The objectives of the current study were to identify profiles of motheradolescent dyads according to foodrelated parenting practices and to determine whether profiles differed in terms of diet quality, family meal frequency, life satisfaction, family and food-related life satisfaction, and sociodemographic characteristics.

\section{METHODS}

The researchers used nonprobability sampling to recruit a sample of 300 2-parent families with at least 1 child aged $>10$ years in Temuco, Chile. Participants aged $\geq 10$ years were recruited with director authorization from 7 schools that served socioeconomically diverse populations.

Because most studies rely on only the parental assessment of the child's behavior, which may not reflect the child's actual behavior or diet, ${ }^{33}$ mothers and their adolescent children were surveyed. Mothers were contacted by trained interviewers who explained the study objectives and the strictly confidential treatment of the information obtained. Interviews were conducted in 
participants' homes or schools according to the preference of participants. After mothers and children signed written consent forms, the questionnaires were personally and separately administered to the mothers and to 1 child aged $>10$ years by trained interviewers from June to December, 2016. The methodology of the study was approved by the Ethics Committee of the Universidad de La Frontera.

A pilot test of the questionnaires was conducted with 10 families that had the same characteristics and followed the same method as families on the definitive survey. Because the pilot test was satisfactory, no changes were required in either the questionnaires or the interview procedure.

The questionnaires included several instruments, which were answered by participating mothers and children.

\section{Abbreviated Family Food Behavior Survey}

The Abbreviated Family Food Behavior Survey (AFFBS) is an adaptation of the Family Food Behavior Survey proposed by McCurdy and Gorman. ${ }^{25}$ It was adapted by Schnettler et al (unpublished) for Spanish-speaking populations. The AFFBS consists of 9 items grouped into 3 dimensions to assess family mealtime practices using a 5-level Likert scale $(0=$ never true; $4=$ always true). The first factor corresponds to maternal control of child snacking behavior (I decide my child's snack time, I decide how many snacks my child has, and I decide what my child eats between meals). The second corresponds to maternal presence during eating (My child and I sit and eat together, I sit down with my child when she or he eats, and I eat dinner with my child) and child involvement in food consumption (My child chooses food items while shopping, My child chooses foods from what is served, and My child chooses which food to have for meals). Schnettler et al (unpublished) adapted a version for children (eg, My mother decides my snack time). Cronbach $\alpha$ ranged from .65 to .79 in the study by Schnettler et al (unpublished) with mother and adolescent samples.

\section{Satisfaction With Life Scale}

The Satisfaction with Life Scale $(\mathrm{SWLS})^{15}$ consists of 5 items grouped into a single dimension to evaluate overall cognitive judgments about a person's own life (eg, In most ways, my life is close to my ideal).

\section{Satisfaction With Food-Related Life}

Satisfaction With Food-Related Life $(\mathrm{SWFoL})^{16}$ is a scale consisting of 5 items grouped into a single dimension to evaluate a person's overall assessment regarding their food and eating habits (eg, Food and meals are positive elements).

\section{Satisfaction With Family Life}

Satisfaction with Family Life (SWFaL) ${ }^{34}$ is a modified version of the SWLS ${ }^{15}$ in which the words family life replace the word life in each of the 5 original SWLS items.

Respondents were asked to indicate agreement with the 5 statements of the SWLS, SWFoL, and SWFaL scales using a 6-level Likert scale ( $1=$ completely disagree; $6=$ completely agree). This study used the Spanish-language versions of the SWLS, SWFoL, and SWFaL which showed good internal consistency in previous studies in Chile. ${ }^{10,17,18,35}$ The SWLS, SWFoL, and SWFaL scores are the sum of the 5 items of each scale. For each scale, higher scores indicate higher satisfaction. The theoretical score for each scale ranged between 5 and 30. In this study, the SWLS (Cronbach $\alpha$ mothers $=.903 ;$ children $=.910)$, SWFoL (Cronbach $\alpha$ mothers $=.864$; children $=.906$ ), and SWFaL (Cronbach $\alpha$ mothers $=.927 ;$ children $=.923$ ) showed good levels of internal consistency. The discriminant validity of the 3 scales was previously demonstrated in university student ${ }^{35}$ and adolescent ${ }^{5}$ samples.

\section{Spanish Version of the Healthy Eating Index}

The Spanish version of the Healthy Eating Index (SHEI) corresponds to an adaption of the US-Healthy Eating Index $^{36}$ realized by Norte and Ortiz ${ }^{37}$ for Spanish-speaking populations. This version was previously used by the Chilean Ministry of Health to measure the overall quality of food consumed by the Chilean population. ${ }^{38}$ Respondents had to answer regarding the consumption frequency for 9 food groups. Each group received a score ranging from 0 to 10 according to the degree of compliance with food recommendations (see food groups and score criteria in Norte and Ortiz). In this study, the SHEI (Cronbach $\alpha$ mothers $=.701 ; \quad$ children $=.700$ ) showed an adequate level of internal consistency. The SHEI score was calculated by adding the score obtained from each variable, for a maximum of 100 points. In this index, scores of $>80$ indicate a healthy diet, 51-80 indicate a diet that requires changes, and $<50$ indicate an unhealthy diet.

Finally, mothers and children were asked their age. Mothers were asked about the number of children, the number of days per week the family shared meals, the family member who was responsible for making food decisions, and the gender of the main breadwinner. Mothers and children were asked to indicate their own approximate weight and height, to determine their body mass index (BMI) $\left(\mathrm{kg} / \mathrm{m}^{2}\right)$. The education level and occupation of the head of household were used to determine socioeconomic status (SES). ${ }^{39}$

A principal component factor analysis (PCA) with varimax rotation (Kaiser normalization) was used and followed by a confirmatory factor analysis (CFA) to verify the underlying components of the AFFBS in mother and adolescent samples. The researchers carried out PCA for the total samples of mothers and adolescents $(n=300)$, whereas they conducted CFA on randomly obtained subsamples of 150 mothers and adolescents.

The PCA was implemented using the Statistical Package for Social Sciences (version 23, SPSS, IBM Corp., Armonk, NY, 2014). The following standards were followed when PCA was performed: the eigenvalues of each extracted factor should be $>1.000$; the factor loadings of each reserved item should be $>0.40$; each item should be loaded on only a single factor; each factor should include $\geq 3$ items. To determine the adequacy of the factor analysis, the researchers used the Kaiser-Meyer-Olkin (KMO) test and Bartlett's test of sphericity; KMO values close to 1 indicate that the PCA is 
adequate, and Bartlett's test is used to verify whether the matrix of correlations between variables is an identity matrix. The higher the value of $\chi^{2}$ and the lower the degree of significance, the less likely that the matrix is an identity matrix. ${ }^{40}$

The CFA was performed using LISREL software (version 8.8, Scientific Software International, Inc, Chicago, IL, 2007). Parameters were estimated by robust maximum likelihood. In terms of construct validity, convergent validity was assessed by inspecting the standardized factor loadings of each factor (ideally, >0.5) as well as their significance, composite reliability (values $>0.7$ ), and average variance extracted (AVE) (values > 0.5). ${ }^{41}$ Discriminant validity was obtained by comparing the AVE for each construct with the square of the correlation between the scales. ${ }^{41}$ Various indicators were used to evaluate the goodness of fit of the model: the comparative fit index (CFI), the goodness-of-fit index (GFI), the adjusted goodness-of-fit index (AGFI), and the root mean square error of approximation (RMSEA). A model fits reasonably well if CFI, GFI, and AGFI are $>0.90$ and if the RMSEA is $<0.08 .{ }^{42}$

To identify families with different profiles, a hierarchical cluster analysis was used on the z-scores of AFFBS components of mothers and children, based on squared Euclidean distances and Ward's method. ${ }^{40}$ The number of clusters was determined by the change in percentage of the recomposed conglomeration coefficients. To define segments, Pearson's $\chi^{2}$ test was used for discrete variables and an ANOVA was performed for continuous variables. Because the Levene's statistic indicated nonhomogeneous variances in each continuous variable observed, the variables that resulted in significant differences were subjected to Dunnett's T3 multiple comparisons test. Data were analyzed using SPSS.

\section{RESULTS}

In the total sample, the average number of children per household was $2.4(\mathrm{SD}=0.9)$. The average age was $41.6(\mathrm{SD}=6.8)$ for mothers and 13.2 $(\mathrm{SD}=2.3)$ for adolescents. Almost half $(48.7 \%)$ of the adolescents were female.
A total of $17.0 \%$ of the families belonged to high and upper-middle SES, $18.7 \%$ to middle, $35 \%$ to lower-middle, $24.0 \%$ to low, and $5.3 \%$ to very low SES. Moreover, $80 \%$ of the families had a man as the main breadwinner.

According to the criteria of the World Health Organization, ${ }^{43}$ 24\% of the mothers surveyed had a BMI in the normal range (18.5-24.9), 42.7\% were overweight (25.0-29.9), and 33.3\% were obese $(\geq 30)$. According to the criteria of the World Health Organization ${ }^{44}$ and the Technical Norm of Nutritional Evaluation for children aged 5-19 years of the Chilean Ministry of Health, ${ }^{45} 6.3 \%$ of adolescents had a BMI that denoted being undernourished $(\leq-2 \mathrm{SD})$ and $13.7 \%$ underweight ( $\leq-1$ to $-1.9 \mathrm{SD})$; $53.7 \%$ were in the normal range $(+0.9$ to $-0.9 \mathrm{SD}$ ) whereas $19.7 \%$ were overweight ( $\geq+1$ to $+1.9 \mathrm{SD})$ and $6.7 \%$ were obese $(\geq+2$ SD).

The SHEI mean score for all mothers was $64.5(\mathrm{SD}=14.3)$ and 62.0 for all children $(\mathrm{SD}=15.0)$, which corresponded to a diet that required changes. All family members had breakfast together an average of 4.2 $\mathrm{d} / \mathrm{wk}(\mathrm{SD}=2.8)$, lunch on $4.4 \mathrm{~d} / \mathrm{wk}$ $(\mathrm{SD}=2.6)$, and dinner on $6.1 \mathrm{~d} / \mathrm{wk}$ $(\mathrm{SD}=1.9)$. The average total number of days when all family members shared these meals corresponded to $14.7(\mathrm{SD}=5.9)$. The main person responsible for making food decisions was the mother $(67.9 \%)$, followed by both parents $(25.3 \%)$ and the father $(4.8 \%)$.

In the total sample, the average SWLS score for mothers was 23.8 $(\mathrm{SD}=4.8)$ and was $24.3(\mathrm{SD}=5.5)$ for children. The average SWFoL score for mothers was $22.8(\mathrm{SD}=4.7)$ and was $22.8(\mathrm{SD}=6.2)$ for children. The average SWFaL score for mothers was $24.4(\mathrm{SD}=4.9)$ and was $24.5(\mathrm{SD}=5.6)$ for children.

Using a PCA, 3 AFFBS components were obtained with eigenvalues $>1$ in both samples $(n=300)$. The values of the KMO sample adequacy test were good, and Bartlett's tests of sphericity were significant $(P \leq .001)$ in both samples. The 3 components represent $67.4 \%$ and $63.6 \%$ of the explained variance, respectively. The maternal control of child snacking behavior (control) component (Cronbach $\alpha$ : mothers $=.810$; children $=.793)$, the maternal presence during eating (presence) component (Cronbach $\alpha$ : mothers $=.758$; children $=.725)$, and child involvement in food consumption (choice) component (Cronbach $\alpha$ : mothers $=.711 ; \quad$ children $=.702$ ) showed acceptable levels of internal consistency. Results for CFA indicated that the composite reliability of the control (mothers $=.812$; children $=.790$ ), presence (mothers $=.780$; children $=.740)$, and choice (mothers $=.700$; children $=.702)$ components of the FFBS were good in both subsamples $(\mathrm{n}=150$ for mothers and children). The 3 components also satisfied the AVE values (control mothers $=.545$, control children $=.555$; presence mothers $=.550$, presence children $=.501$; choice mothers $=.500$, choice children $=.501$ ) in both subsamples. The standardized factor loadings for all items in each factor were $>0.5$ and statistically significant. Thus, the researchers concluded that there was convergent validity in both subsamples. The value of the squared correlations between control and presence (mothers $=.080$; children $=.111$ ) were lower than the AVE of the factors, which verified the discriminant validity between the constructs in both subsamples. The discriminant validity between control and child (mothers $=.090$; children $=.121$ ) and between presence and child ( mothers $=.124$; children $=.097)$ was also verified. ${ }^{41}$ The CFA performed with the 9 items of the FFBS showed that the 3-component structure found using PCA could be validated with a satisfactory goodness-of-fit in mothers $(\mathrm{RMSEA}=0.035$; CFI $=0.99$; $\mathrm{GFI}=0.98$; $\mathrm{AGFI}=0.97)$ and children (RMSEA $=0.050 ; \mathrm{CFI}=0.96$; $\mathrm{GFI}=0.96 ;$ AGFI $=0.94)$ subsamples. There were no significant differences in the 3 component $\mathrm{z}$-scores between mother and children samples $(P>.1)$.

Cluster analysis identified 3 profiles of mother-adolescent dyads with different food-related parenting practices. Dyads in group 1 (32.6\%) were characterized by low scores in the 3 AFFBS components, with the lowest scores observed for presence in both samples (Table 1). Thus, group 1 can be described as mothers with low foodrelated parenting practices. Dyads in group $2(37.7 \%)$ had higher scores on presence, but the highest scores were 
Table 1. Mean z-Scores and SDs of Maternal Control of Child Snacking Behavior (Control), Maternal Presence During Eating (Presence), and Child Involvement in Food Consumption (Choice) Components of Abbreviated Family Food Behavior Survey for Mothers and Children in 3 Clusters

\begin{tabular}{|c|c|c|c|c|c|}
\hline Component & $\begin{array}{c}\text { Group } 1(n=98) \\
\text { Mothers With Low } \\
\text { Food-Related } \\
\text { Parenting Practices }\end{array}$ & $\begin{array}{c}\text { Group } 2(n=113) \\
\text { Present and } \\
\text { Controlling Mothers }\end{array}$ & $\begin{array}{l}\text { Present and } \\
\text { Uncontrolling } \\
\text { Mothers, Children } \\
\text { Involved in Food } \\
\text { Consumption }\end{array}$ & $\mathbf{F}$ & $P$ \\
\hline \multicolumn{6}{|l|}{ Mothers } \\
\hline Control & $-0.168^{b}(0.740)$ & $0.745^{a}(0.584)$ & $-0.74^{c}(1.043)$ & 91.163 & $<.001$ \\
\hline Presence & $-0.974^{b}(0.888)$ & $0.574^{\mathrm{a}}(0.410)$ & $0.458^{a}(0.736)$ & 154.180 & $<.001$ \\
\hline Choice & $-0.272^{\mathrm{b}}(0.770)$ & $-0.179^{b}(0.008)$ & $0.338^{a}(0.143)$ & 10.430 & $<.001$ \\
\hline \multicolumn{6}{|l|}{ Children } \\
\hline Control & $-0.298^{b}(0.940)$ & $0.728^{a}(0.732)$ & $-0.496^{b}(0.891)$ & 62.137 & $<.001$ \\
\hline Presence & $-0.514^{b}(0.128)$ & $0.224^{a}(0.838)$ & $0.415^{\mathrm{a}}(0.682)$ & 28.351 & $<.001$ \\
\hline Choice & $-0.028(0.817)$ & $-0.068(0.079)$ & $-0.115(0.074)$ & 0.172 & .84 \\
\hline
\end{tabular}

Different superscript letters line indicate significant differences according to Dunnett's T3 multiple comparisons test.

observed for control in both samples. Therefore, group 2 can be labeled as present and controlling mothers. Dyads in group 3 (29.7\%) were characterized by the lowest scores for control in both samples and the highest scores for choice in the mothers' sample. Thus, group 3 can be called present and uncontrolling mothers, children involved in food consumption. The groups did not differ in choice scores in the children subsample. Within the mothers with low food-related parenting practices group, the presence $(P=.002)$ and choice $(P=.03)$ scores from children were significantly higher than those of their mothers. Within the present and controlling mothers group, the presence score from mothers $(P<.001)$ was significantly higher than the presence score from children. Within the present and uncontrolling mothers, children involved in food consumption group, the choice score from mothers $(P=.007)$ was significantly higher than the choice score from children.

Mothers and children from the mothers with low food-related parenting practices group and the present and uncontrolling mothers, children involved in food consumption group had a higher average age than did those from the present and controlling mothers group (Table 2).
Mothers and children from the present and controlling mothers group had the highest SHEI scores (Table 2). Mothers from the mothers with low food-related parenting practices group had the lowest SHEI score, although it did not differ from the present and uncontrolling mothers, children involved in food consumption group (Table 2). Children from the present and uncontrolling mothers, children involved in food consumption group had the lowest SHEI score, although it did not differ from that in the mothers with low food-related parenting practices group. The SHEI scores from mothers and children in the 3 groups indicated diets that required changes. Differences in SHEI scores among the 3 groups of dyads were explained by differences in the frequency of consumption of different food groups (Table 3). The mothers with low food-related parenting practices group had the lowest proportion of mothers and children who consumed vegetables daily. The present and controlling mothers group had the greater proportion of mothers who never consumed sweets, or almost never did, and the highest proportion of children who consumed vegetables daily. The present and controlling mothers group also had the greatest proportion of children who consumed fruits daily, compared with the other 2 groups. In addition, the present and controlling mothers group had the greatest proportion of children who consumed milk and dairy products daily, whereas the present and uncontrolling mothers, children involved in food consumption group had the lowest (Table 3). Mothers and children in the present and controlling mothers group had the highest average diet variety scores (Table 2 ).

The present and controlling mothers group and the present and uncontrolling mothers, children involved in food consumption group had meals together (including breakfast, lunch, and dinner) significantly more often than did the mothers with low food-related parenting practices group (Table 2). The mothers with low food-related parenting practices group was composed of a greater proportion of families $(10.4 \%)$ in which the father decided which foods to purchase for the household $(P=.02)$.

The average SWLS, SWFoL, and SWFaL scores of mothers from the present and controlling mothers group and the present and uncontrolling mothers, children involved in food consumption group were significantly higher than were scores from the mothers with low food-related parenting practices group. The average SWLS, SWFoL, and SWFaL scores for children from the present and 
Table 2. Means and SDs for Age, Spanish Version of Healthy Eating Index (SHEI), Diet Variety Score, Number of Days Each Week Families Ate Together, Satisfaction With Life scale (SWLS), Satisfaction With Food-Related Life (SWFoL), and Satisfaction With Family Life (SWFaL) Scales of Mothers and Children of 3 Groups of MotherAdolescent Dyads With Different Food-Related Parenting Practices Identified Using Hierarchical Cluster Analysis

\begin{tabular}{|c|c|c|c|c|c|}
\hline Component & $\begin{array}{l}\text { Group } 1(n=98) \\
\text { Mothers With Low } \\
\text { Food-Related } \\
\text { Parenting Practices }\end{array}$ & $\begin{array}{l}\text { Group } 2(n=113) \\
\text { Present and } \\
\text { Controlling Mothers }\end{array}$ & $\begin{array}{l}\text { Uncontrolling } \\
\text { Mothers, Children } \\
\text { Involved in Food } \\
\text { Consumption }\end{array}$ & $\mathbf{F}$ & $P$ \\
\hline \multicolumn{6}{|l|}{ Age, y } \\
\hline Mother & $42.7^{\mathrm{a}}(6.7)$ & $40.3^{b}(7.0)$ & $42.0^{\mathrm{a}}(6.4)$ & 3.632 & .03 \\
\hline Adolescent & $13.5^{a}(2.3)$ & $12.3^{b}(2.1)$ & $14.0^{\mathrm{a}}(2.2)$ & 15.549 & $<.001$ \\
\hline \multicolumn{6}{|l|}{ SHEI } \\
\hline Mother & $60.9^{b}(14.5)$ & $67.9^{a}(13.4)$ & $64.1^{\mathrm{a}, \mathrm{b}}(14.3)$ & 6.592 & .002 \\
\hline Adolescent & $59.5^{\mathrm{b}}(15.3)$ & $66.6^{a}(13.3)$ & $58.8^{b}(15.3)$ & 9.272 & $<.001$ \\
\hline \multicolumn{6}{|l|}{ SHEI diet variety score } \\
\hline Mother & $3.4^{\mathrm{b}}(2.8)$ & $4.6^{\mathrm{a}}(2.6)$ & $4.1^{\mathrm{a}, \mathrm{b}}(2.9)$ & 5.012 & .007 \\
\hline Adolescent & $3.6^{\mathrm{b}}(2.5)$ & $5.3^{\mathrm{a}}(2.4)$ & $3.6^{b}(2.6)$ & 16.127 & $<.001$ \\
\hline $\begin{array}{l}\text { Families ate together } \\
\text { (breakfast, lunch and } \\
\text { dinner), d/wk }\end{array}$ & $12.5^{b}(6.0)$ & $16.2^{\mathrm{a}}(5.4)$ & $15.1^{\mathrm{a}}(5.9)$ & 10.718 & $<.001$ \\
\hline \multicolumn{6}{|l|}{ SWLS } \\
\hline Mother & $22.1^{b}(5.0)$ & $24.8^{a}(4.5)$ & $24.5^{\mathrm{a}}(4.6)$ & 10.212 & $<.001$ \\
\hline Children & $23.4^{b}(4.6)$ & $25.5^{\mathrm{a}}(5.7)$ & $23.7^{\mathrm{b}}(6.1)$ & 4.408 & .01 \\
\hline \multicolumn{6}{|l|}{ SWFoL } \\
\hline Mother & $20.8^{b}(4.9)$ & $23.7^{\mathrm{a}}(4.5)$ & $23.8^{\mathrm{a}}(4.2)$ & 13.882 & $<.001$ \\
\hline Children & $21.7^{\mathrm{b}}(5.7)$ & $24.1^{a}(5.9)$ & $22.4^{\mathrm{b}}(6.8)$ & 4.145 & .02 \\
\hline \multicolumn{6}{|l|}{ SWFaL } \\
\hline Mother & $22.7^{b}(5.5)$ & $25.1^{\mathrm{a}}(5.0)$ & $25.4^{\mathrm{a}}(3.8)$ & 8.835 & $<.001$ \\
\hline Children & $23.8^{b}(4.6)$ & $25.8^{\mathrm{a}}(5.1)$ & $23.8^{b}(6.7)$ & 5.110 & .007 \\
\hline
\end{tabular}

Different superscript letters indicate significant differences according to Dunnett's T3 multiple comparisons test.

controlling mothers group were significantly higher than were those in the mothers with low food-related parenting practices and present and uncontrolling mothers, children involved in food consumption groups (Table 2).

Finally, no significant differences were found between groups for the number of children, the gender of the surveyed children, mothers' and children's BMI, SES, or the gender of the main breadwinner $(P>.1)$.

\section{DISCUSSION}

The current study focuses on identifying profiles of mother-adolescent dyads according to food-related parenting practices, to determine whether these profiles differed. Accordingly, 3 profiles were identified. Group 1 had low scores for the 3 AFFBS components, reflecting mothers with low food-related parenting practices. Group 2 scores suggested present and controlling mothers. Group 3 scores showed present and uncontrolling mothers with children involved in food consumption.

Nevertheless, the comparison of the AFFBS components scores between mothers and children showed that in the group of mothers with low food-related parenting practices, the mothers' perceptions about their presence during child food consumption were more negative than were their children's perceptions, ie, children perceived that their mothers were more present during meals than their mothers perceived themselves to be. In the group of present and controlling mothers, mothers' perceptions about their presence when children ate were more positive than were their children's perceptions, ie, children perceived that their mothers were less present during meals than their mothers perceived themselves to be. In the group of present and uncontrolling mothers, children involved in food consumption, the mothers' perceptions regarding child 
Table 3. Frequency of Consumption of Foods Considered in Spanish Version of Healthy Eating Index With Statistical Differences Among Mothers and Among Children for 3 Clusters Identified

Food

Mothers

Vegetables

Daily consumption

$\geq 3$ times/wk but not daily

Once or twice/wk

Less than once/wk

Sweets

Daily consumption

$\geq 3$ times/wk but not daily

Once or twice/wk

Less than once/wk

Never or almost never

\section{Children}

Vegetables

Daily consumption

$\geq 3$ times/wk but not daily

Once or twice/wk

39.8

19.4

Less than once/wk

Never or almost never

Fruit

Daily consumption

$\geq 3$ times/wk but not daily

Once or twice/wk

Less than once/wk

Never or almost never

Milk and dairy products

Daily consumption
$\geq 3$ times/wk but not daily
Once or twice/wk
Less than once/wk
Never or almost never

\section{Group $1(n=98)$ \\ Mothers With Low \\ Food-Related \\ Parenting Practices}

\section{Group 3 ( $n=89)$ \\ Present and Uncontrolling Mothers, Children Involved in Food Consumption}

$\begin{array}{rcr}49.0 & 64.6 & 61.8 \\ 29.6 & 27.4 & 30.3 \\ 19.4 & 6.2 & 6.7 \\ 2.0 & 1.8 & 1.1 \\ & P=.002 & \\ 8.2 & 3.5 & 11.2 \\ 23.5 & 15.0 & 19.1 \\ 32.7 & 22.1 & 21.3 \\ 24.5 & 25.7 & 15.7 \\ 11.2 & 33.6 & 32.6\end{array}$

\section{Present and \\ Controlling Mothers}

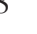


did to affect their eating habits and what parents reported they did. ${ }^{33}$

The groups' SHEI scores partially confirmed previous findings regarding the positive association between high family meal frequency and healthier adolescent diets. ${ }^{1-4}$ However, they also seemed to confirm the lack of association when healthful parenting practices are low. ${ }^{3}$ The low SHEI scores from the mothers with low food-related parenting practices group were consistent with their lower frequency of family meals, and the higher SHEI scores from the present and controlling mothers group were congruent with their higher frequency of family meals. At the same time, these findings were congruent with those of studies stressing that parental influence via food-related parenting practices is based on parental presence and parental involvement in family meals, ${ }^{3}$ given that a low frequency of family meals $s^{3,26}$ was associated with less parental monitoring and control over meals. ${ }^{3}$ Nevertheless, although the present and uncontrolling mothers, children involved in food consumption group had family meal frequencies similar to those of the present and controlling mothers group, the SHEI score from children in the present and uncontrolling mothers, children involved in food consumption group was the lowest and was similar to that of the mothers with low food-related parenting practices group. Therefore, it seems that frequent family meals and maternal presence when children eat are not enough to improve family members' diet quality. ${ }^{5,6}$ It is also necessary for parents to monitor or control their adolescent children's meals. ${ }^{3}$ In other words, more frequent family meals could result in a better diet quality only if parents use adequate food-related parenting practices during family meals. Along this same line, the differences in SHEI scores between children from the present and controlling mothers group and the present and uncontrolling mothers, children involved in food consumption group may be related to the control scores of these groups, which may be related to differences in the control of healthy food consumption. These results confirm the findings of studies that associated a lower intake of fruits and vegetables with less parental control over meals. ${ }^{3,23}$ Nevertheless, these results contradict evidence indicating that higher levels of parental control are related to increased adolescent consumption of unhealthy foods and overeating, ${ }^{21,24}$ thereby increasing adolescent BMI. ${ }^{21}$ One possible explanation for the findings of the current study may be related to differences in the ages of the adolescent children in the present and controlling mothers group and the present and uncontrolling mothers, children involved in food consumption group. ${ }^{1}$ As children age, they are more likely to choose their own foods and meals and to obtain food outside the home. ${ }^{2}$ Therefore, it is possible that maternal control over older adolescents may be ineffective, causing mothers to decrease their control over their children's diet and increase their involvement in household food choices. Some studies show that increased child influence in food planning and preparation results in less healthy food choices. ${ }^{23}$ This is consistent with the low consumption of fruit, milk, and dairy products in children from the present and uncontrolling mothers, children involved in food consumption group. Nevertheless, the findings of this study also contradict researchers who found that adolescent involvement in food preparation was a positive factor affecting diet quality among this age group. ${ }^{3,21} \mathrm{Al}-$ though both results related to control and children food involvement confirmed that food-related parenting practices may have positive and negative effects on adolescent eating habits, ${ }^{3,12,21-24}$ the existing yet inconclusive evidence may be associated with cultural aspects related to foodrelated parenting practices. ${ }^{46}$

The low SHEI score and low vegetable and fruit consumption in children from the mothers with low food-related parenting practices group were consistent with low maternal presence during mealtime ${ }^{4}$ and the low control score in this group, which supports evidence associating the lower intake of fruits and vegetables with less parental control over meals. ${ }^{3,23} \mathrm{Nev}$ ertheless, other differences in food consumption suggest that the SHEI score discrepancies between groups may be associated with food-related parenting practices not measured by the AFFBS. Parents providing healthy foods at home $e^{1,3,4}$ and modeling healthy eating practices ${ }^{1,4,20,22,47}$ have an important role in children's healthy eating habits. The lack of these practices may explain the low frequency of vegetable consumption and low SHEI scores in the mothers and children from the mothers with low foodrelated parenting practices group, because it seems that those mothers did not model vegetable consumption or provide enough vegetables at home. In that group, a higher proportion of fathers were responsible for deciding what to eat. This finding may be related to the lack of time mothers from the mothers with low foodrelated parenting practices group had, owing to job-related issues. Nevertheless, contrary to was expected, ${ }^{3,6,48}$ no differences were found between groups in the gender of the main breadwinner. Therefore, more research is needed to find the causes for the low presence of these mothers during meals and their lower participation in food purchasing decisions.

Some authors suggested that family meals may provide a unique opportunity for building stronger families and young people, owing to the benefits frequent family meals may offer young people that extend beyond good nutrition. ${ }^{11}$ Accordingly, the SWLS, SWFoL, and SWFaL scores from the mothers with low food-related parenting practices group and the present and controlling mothers group confirm previous studies that associated more frequent family meals with increased well-being in children, ${ }^{11-13}$ as well as maternal well-being and in the domains of food ${ }^{10,18}$ and family. ${ }^{5}$ In this regard, there is evidence that family meals may lead to more connected and communicative families in which children can talk with their parents about their problems. This, in turn, may lead to more positive experiences that increase adolescent well-being, ${ }^{11,12}$ given the positive association with family support. $5,10,11,18,19$ In fact, various studies reported that adults and emerging adults who share meals with their family more often are more satisfied with their life and their food-related life, which suggests that mealtime is the moment when all family members offer support to one 
another, specifically from parents to their children. This positively affects adolescents' levels of life satisfaction, food-related life satisfaction, 5,10,18,19 and satisfaction with family life. ${ }^{5}$ The characteristics of the mothers with low food-related parenting practices group and the present and controlling mothers group also confirm that levels of life satisfaction and foodrelated life and family life satisfaction are associated with eating habits. 5,10,18,19 Utter and colleagues ${ }^{13}$ suggested that healthier diets may partially explain the association between family meals and well-being in adolescents. In fact, results from a study carried out with undergraduate students (mean age, 20.1 years) concluded that those with higher levels of life satisfaction and food-related life satisfaction consumed milk or dairy products, fruits, and vegetables daily, whereas students less satisfied with their life and their foodrelated life only occasionally consumed these foods. ${ }^{10}$ More recently, it was reported that adults who were more satisfied with their life, food-related life, and family life had healthier diets than did those who were less satisfied. ${ }^{5}$ Therefore, the current study shows evidence that confirms a relationship between healthier eating habits and higher satisfaction with life and foodrelated and family life in adolescents.

Regarding food-related parenting practices and well-being, higher mother scores on the SWLS, SWFoL, and SWFaL corresponded to the present and controlling mothers group and the present not controlling mothers, children involved in food consumption group, in which the mothers' presence scores were high. The mothers with low food-related parenting practices group had low scores in all of these variables. These findings indicate that a mother's wellbeing is also associated with the frequency of sharing mealtimes with her family, which supports a recent study that reported that adults who share meals with their family more often are more satisfied with their life, food-related life, and family life. ${ }^{5}$ These findings are likely related to the affective dimension of meals as a moment of family unity, when family members can preserve relationship closeness, resolve conflicts, express affection, and provide emotional support. ${ }^{7,8}$ Regarding mothers from the mothers with low food-related parenting practices group, their characteristics may be associated with their lower levels of well-being, which may also be related to mental health issues, such as depression. ${ }^{49}$ In this regard, it has been reported that mothers with depression exert less control over their children's meals and adopt less healthy and more distant food-related parenting practices with their children. ${ }^{50}$ This may also negatively influence their children's well-being. However, because this study did not assess maternal mental health, more research is required to evaluate these relationships.

For children, SWLS, SWFoL, and SWFaL scores from the mothers with low food-related parenting practices group and present and controlling mothers group suggest that maternal presence when children ate was related to their well-being, but not in the present and uncontrolling mothers, children involved in food consumption group. One possible explanation may be related to the age of the adolescents in the present and uncontrolling mothers, children involved in food consumption group, because children may have had the opportunity to share meals with older siblings, which may have decreased the importance of maternal presence during meals. However, another explanation may be related to a negative atmosphere during meals in which mothers are present, negatively affecting adolescent well-being. ${ }^{31}$ Indeed, it was reported that negative experiences during meals may include discussions focused on food choices and weight or observations of physical appearance, among other topics that may reduce adolescent well-being. ${ }^{51}$ Therefore, future research should include an assessment of family meal atmosphere. The significantly higher scores on control, SWLS, SWFoL, and SWFaL in adolescents from the present and controlling mothers group partially agreed with the results reported by Utter and colleagues, ${ }^{11}$ specifically the finding that adolescents who reported more parental monitoring had higher wellbeing scores. One explanation may be associated with how the adolescent perceived parental control as a dem- onstration of concern and affection from parents, which positively affects well-being. Therefore, it is possible that increased maternal control of child snacking behavior may have been perceived positively by adolescents in this group, who may have viewed such behavior as their mothers trying to protect them from becoming overweight or obese. ${ }^{27}$ This would positively affect adolescent well-being. ${ }^{28}$ However, again, more research is needed to understand these relationships better.

The significantly higher score from mothers than children from the present and uncontrolling mothers, children involved in food consumption group in the choice component may reflect that, whereas mothers from this group may have tried to involve their children in food selection, children did not perceive themselves as being more involved in food consumption or want to be more involved. This may partially explain the lower scores of these adolescents in the SWLS, SWFoL, and SWFaL. Although Utter and colleagues ${ }^{13}$ found that adolescent involvement in food preparation was associated with better family relationships and well-being, those authors also reported that adolescents who cooked most days were more likely to report poorer family relationships and lower well-being.

Finally, although high levels of unhealthy food restriction and high parental control were associated with an increase in unhealthy food consumption, , $^{3,9,24}$ the higher control and SHEI scores in children from the present and controlling mothers group indicated the opposite. Likewise, the higher control, SWLS, SWFoL, and SWFaL scores in children from that group seemed to indicate that maternal control of child snacking behavior may be related to a high level of wellbeing. This result was in line with the findings of Utter and colleagues. ${ }^{11}$

The strengths of this study lay in its having surveyed mothers and their children, which allowed the differences in their responses to be evaluated. In addition, validated measures of well-being were used and the study sample included socioeconomically diverse families in a developing country, contributing to the knowledge of food-related parenting practices 
used by mothers outside developed countries. Among the study's limitations are its cross-sectional design, the nonprobabilistic nature of the sample, and its relatively small size, as well as it having been conducted with families from only 1 city in 1 country, which does not permit the generalization of the results. All data were selfreported, and thus responses may have been affected by social desirability. The questionnaire asked for the occupation only of the head of the household; therefore, it is not possible to associate the mothers' foodrelated parenting practices with their job conditions. In addition, only 3 food-related parenting practices were directly studied and neither the atmosphere of family meals nor the mothers' mental health was assessed, which may also have influenced their food-related parenting practices. This study focused on only motheradolescent dyads because of a recent study in Chile that stressed the key role of mothers in determining the diet quality of families. ${ }^{5}$ However, it is wellknown that both mothers and fathers influence their children's eating behavior, and their influence has been reported to differ largely. ${ }^{52}$ Therefore, not having considered the influence of fathers constitutes another limitation of the current study.

\section{IMPLICATIONS FOR RESEARCH AND PRACTICE}

Findings from this study confirm the importance of family meals for improving eating habits and well-being in adolescents and their mothers, as well as in the food and family life domains. Therefore, to promote healthy eating habits within families, frequent family meals are encouraged. This is especially relevant in countries such as Chile, which is ranked sixth in the world for obesity. Therefore, interventions are highly needed to promote healthy and frequent family meals, because the 3 family profiles detected in this study had diets that required changes. These results reflect domestic reality because only $5 \%$ of the Chilean population has a healthy diet, $87 \%$ requires changes, and $8 \%$ has an unhealthy diet, ac- cording to data from the Chilean Ministry of Health. ${ }^{38}$

In addition, findings from this study underscore the fact that foodrelated parenting practices may affect the eating habits and subjective wellbeing of mothers and their children in different ways. Therefore, these findings may be useful for researchers, parents, and health practitioners seeking to develop strategies to improve diet quality, overall wellbeing, and well-being in the food and family domains for all family members.

Future studies should evaluate the relationship between the family meal atmosphere and other food-related parenting practices and subjective wellbeing in mothers and their children; moreover, it should include fathers, given their increasing engagement in child-rearing tasks. ${ }^{47}$ In addition, crosscultural studies are required, because culture is a powerful determinant of food attitudes and behaviors. ${ }^{53}$ Finally, given the possibility that more frequent family meals cause greater life satisfaction, it may also be that those with greater life satisfaction are those with the time to plan family meals and the desire to eat with their family. Further research is required to test causality between frequency of family meals and life satisfaction. To do this, experimental, quasi-experimental, or longitudinal design studies should be performed.

\section{ACKNOWLEDGMENTS}

This work was supported by Conicyt, Fondecyt Project No. 1160005.

\section{REFERENCES}

1. Berge JM, Arikian A, Doherty WJ, Neumark-Sztainer D. Healthful eating and physical activity in the home environment: results from multifamily focus groups. J Nutr Educ Behav. 2012; 44:123-131.

2. Fink SK, Racine EF, Mueffelmann RE, Dean MN, Herman-Smith R. Family meals and diet quality among children and adolescents in North Carolina. J Nutr Educ Behav. 2014;46:418-422.

3. Reicks M, Banna J, Cluskey M, et al. Influence of parenting practices on eating behaviors of early adolescents during independent eating occasions: implications for obesity prevention. Nutrients. 2015;7:8783-8801.

4. Watts AW, Loth K, Berge JM, Larson N, Neumark-Sztainer D. No time for family meals? Parenting practices associated with adolescent fruit and vegetable intake when family meals are not an option. J Acad Nutr Diet. 2017;117:707714.

5. Schnettler B, Lobos G, Miranda-Zapata E, Denegri M, Ares G, Hueche C. Diet quality and satisfaction with life, family life, and food-related life across families: a cross-sectional pilot study with mother-father-adolescent triads. Int $J$ Environ Res Public Health. 2017;14: 1313.

6. Nepper MJ, Chai W. Parents' barriers and strategies to promote healthy eating among school-age children. Appetite. 2016;103:157-164.

7. Speirs KE, Hayes JT, Musaad S, et al. Is family sense of coherence a protective factor against the obesogenic environment? Appetite. 2016;99:268276.

8. Ramalho JDAM, Lachal J, BucherMaluschke JSNF, Moro MR, RevahLevy A. A qualitative study of the role of food in family relationships: an insight into the families of Brazilian obese adolescents using photo elicitation. Appetite. 2016;96:539-545.

9. Haines J, Rifas-Shiman SL, Horton NJ, et al. Family functioning and quality of parent-adolescent relationship: crosssectional associations with adolescent weight-related behaviors and weight status. Int J Behav Nutr Phys Act. 2016; 13:68.

10. Schnettler B, Miranda H, Lobos G, et al. Eating habits and subjective well-being: a typology of students in Chilean state universities. Appetite. 2015;89:203214.

11. Utter J, Denny S, Robinson E, Fleming T, Ameratunga S, Grant S. Family meals and the well-being of adolescents. J Paediatr Child Health. 2013;49:906911.

12. Utter J, Denny S, Lucassen M, Dyson B. Adolescent cooking abilities and behaviors: associations with nutrition and emotional well-being. J Nutr Educ Behav. 2016;48:35-41.

13. Utter J, Denny S, Peiris-John R, Moselen E, Dyson B, Clark T. Family meals and adolescent emotional wellbeing: findings from a national study. J Nutr Educ Behav. 2017;49:67-72. 
14. Diener E, Suh EM, Lucas RE, Smith HL. Subjective well-being: three decades of progress. Psychol Bull. 1999;15:276302.

15. Diener E, Emmons R, Larsen R, Griffin S. The satisfaction with life scale. J Pers Assess. 1985;49:71-75.

16. Grunert KG, Dean M, Raats MM, Nielsen NA, Lumbers M. A measure of satisfaction with food-related life. Appetite. 2007;49:486-493.

17. Schnettler B, Miranda H, Sepúlveda J, et al. Psychometric properties of the Satisfaction with Food-Related Life Scale: application in southern Chile. J Nutr Educ Behav. 2013;45:443-449.

18. Schnettler B, Höger Y, Orellana L, et al. Family eating habits, family support and subjective well-being in university students in Chile. Nutr Hosp. 2016;33:451458.

19. Schnettler B, Denegri M, Miranda H, et al. Family support and subjective wellbeing: an exploratory study of university students in southern Chile. Soc Indic Res. 2015;122:833-864.

20. Berge JM, Trofholz A, Schulte A, Conger K, Neumark-Sztainer D. A qualitative investigation of parents' perspectives about feeding practices with siblings among racially/ethnically and socioeconomically diverse households. $J$ Nutr Educ Behav. 2016;48:496-504.

21. Alm S, Olsen SO, Honkanen P. The role of family communication and parents' feeding practices in children's food preferences. Appetite. 2015;89:112-121.

22. Branch JM, Appugliese DP, Rosenblum KL, Miller AL, Lumeng JC, Bauer $\mathrm{KW}$. Feeding and mealtime correlates of maternal concern about children's weight. J Nutr Educ Behav. 2017;49:490496.

23. Papaioannou MA, Cross MB, Power TG, et al. Feeding style differences in food parenting practices associated with fruit and vegetable intake in children from low-income families. J Nutr Educ Behav. 2013;45:643-651.

24. Stok FM, de Vet E, de Wit JB, Renner B, de Ridder DT. Communicating eating-related rules: suggestions are more effective than restrictions. Appetite. 2015; 86:45-53.

25. McCurdy K, Gorman KS. Measuring family food environments in diverse families with young children. Appetite. 2010;54:615-618.

26. Jarosz E. Class and eating: family meals in Britain. Appetite. 2017;116:527535.
27. Chong SY, Chittleborough CR, Gregory T, Lynch JW, Mittinty MN, Smithers LG. Associations of parental food-choice control and use of food to soothe with adiposity in childhood and adolescence. Appetite. 2017;113:71-77.

28. Proctor CL, Linley PA, Maltby J. Youth life satisfaction: a review of the literature. J Happiness Stud. 2009;10:583630.

29. Pesch MH, Rizk M, Appugliese DP, Rosenblum KL, Miller A, Lumeng JC. Maternal concerns about children overeating among low-income children. Eat Behav. 2016;21:220-227.

30. Houldcroft L, Farrow C, Haycraft E. Perceptions of parental pressure to eat and eating behaviours in preadolescents: the mediating role of anxiety. Appetite. 2014;80:61-69.

31. Salafia EHB, Lemer JL. Associations between multiple types of stress and disordered eating among girls and boys in middle school. J Child Fam Stud. 2012; 21:148-157.

32. González-Carrasco M, Casas F, Viñas F, Malo S, Gras ME, Bedin L. What leads subjective well-being to change throughout adolescence? An exploration of potential factors. Child Indic Res. 2017; 10:33-56.

33. Fries LR, Martin N, van der Horst K. Parent-child mealtime interactions associated with toddlers' refusals of novel and familiar foods. Physiol Behav. 2017; 176:93-100.

34. Zabriskie R, McCormick B. Parent and child perspectives of family leisure involvement and satisfaction with family life. J Leisure Res. 2003;35:163-189.

35. Schnettler B, Miranda-Zapata E, Grunert $\mathrm{KG}$, et al. Life satisfaction of university students in relation to family and food in a developing country. Front Psychol. 2017;8:1522.

36. Kennedy ET, Ohls J, Carlson S, Fleming $\mathrm{K}$. The healthy eating index: design and applications. J Am Diet Assoc. 1995;95: 1103-1108.

37. Norte AI, Ortiz R. Calidad de la dieta española según el índice de alimentación saludable. Nutr Hosp. 2011;26:330336, [in Spanish].

38. Ministerio de Salud de Chile. Encuesta Nacional de Consumo Alimentario; 2014. http://web.minsal.cl/sites/default/ files/ENCA-INFORME_FINAL.pdf. Accessed November 25, 2016.

39. Adimark. Mapa Socioeconómico de Chile. http://www.adimark.cl. Accessed December 30, 2015.
40. Hair J, Anderson R, Tatham R, Black W. Análisis Multivariante. Madrid, Spain: Prentice Hall; 2007.

41. Lévy J-P, Varela J. Modelización con Estructuras de Covarianzas en Ciencias Sociales: Temas Esenciales, Avanzados y Aportaciones Especiales. Madrid: Netbiblo; 2006.

42. Kline RB. Principles and Practice of Structural Equation Modelling. New York, NY: Guilford Press; 2011.

43. World Health Organization. Expert consultation. appropriate body-mass index for Asian populations and its implications for policy and intervention strategies. Lancet. 2004;10:157-163.

44. World Health Organization. Child growth and development. http:// www.who.int/childgrowth/en/.

Accessed May 26, 2016.

45. Ministerio de Salud de Chile. Orientaciones Técnicas para el Control de Salud Integral de Adolescentes. http:// web.minsal.cl/wp-content/uploads/ 2015/09/OT-CONTROL-DESALUD-INTEGRAL-FINAL.pdf. Accessed May 26, 2016.

46. Loth KA, MacLehose RF, Fulkerson JA, Crow S, Neumark-Sztainer D. Eat this, not that! Parental demographic correlates of food-related parenting practices. Appetite. 2013;60:140-147.

47. Vaughn AE, Dearth-Wesley T, Tabak RG, Bryant M, Ward DS. Development of a comprehensive assessment of food parenting practices: the home selfadministered tool for environmental assessment of activity and diet family food practices survey. J Acad Nutr Diet. 2017; 117:214-227.

48. CASEN. Equidad de género. Síntesis de resultados. http://observatorio .ministeriodesarrollosocial.gob.cl/casenmultidimensional/casen/docs/CASEN _2015_Resultados_equidad_genero.pdf. Accessed July 31, 2017.

49. Luthar SS, Ciciolla L. Who mothers mommy? Factors that contribute to mothers' well-being. Dev Psychol. 2015; 51:1812-1823.

50. McCurdy K, Gorman KS, Kisler T, Metallinos-Katsaras E. Associations between family food behaviors, maternal depression, and child weight among low-income children. Appetite. 2014;79: 97-105.

51. Berge JM, MacLehose R, Loth KA, Eisenberg M, Bucchianeri MM, Neumark-Sztainer D. Parent conversations about healthful eating and weight: associations with adolescent disordered 
eating behaviors. JAMA Pediatr. 2013; 167:746-753.

52. Hebestreit $A$, Intemann $T$, Siani $A$, et al. Dietary patterns of European children and their parents in association with family food environment: results from the I. Family study. Nutrients. 2017;9: 126.
53. Rozin P. The meaning of food in our lives: a cross-cultural perspective on eating and well-being. J Nutr Educ Behav. 2005; 37(suppl 2):S107-S112.

\section{JNEB Webinar: Implementation Science for Nutrition Education Professionals and Researchers}

September 18 at 11:00 am Central

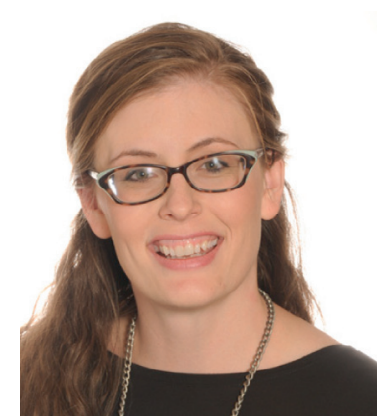

Taren Swindle, PhD, presenter

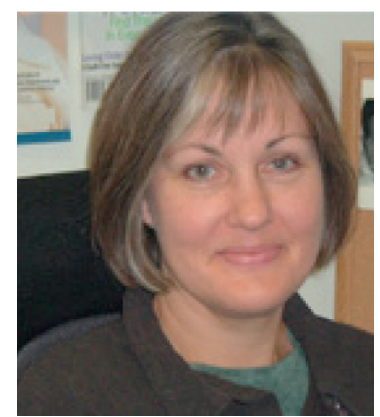

Susan Johnson, PhD, moderator

Implementation Science (IS) is the study of how best to support uptake and sustainability of evidence-based and recommended practices. To date, application of IS principles and designs have been limited in the nutrition education field. This webinar will explore the relevance of IS for advancing the field of nutrition education. Attendees will become familiar with scenarios fitting for application of IS. Further, IS methods will be compared to terminology and concepts likely to be familiar to nutrition education audiences (e.g., process evaluation). 